\title{
Confirmation of the posterior gastric artery using multi-detector row computed tomography
}

\author{
Takehiro Okabayashi ${ }^{1}$, Michiya Kobayashi ${ }^{1}$, Satoshi Morishita ${ }^{2}$, Takeki Sugimoto ${ }^{1}$, Toyokazu Akimori ${ }^{1}$, \\ Tsutomu Namikawa ${ }^{1}$, Ken Okamoto ${ }^{1}$, Norihiro Hokimoto ${ }^{1}$, and KeiJiro Araki ${ }^{1}$ \\ ${ }^{1}$ Department of Surgery, Kochi Medical School, Kohasu-Okocho, Nankoku, Kochi 783-8505, Japan \\ ${ }^{2}$ Radiology Division, Kochi Medical School, Kochi, Japan
}

\begin{abstract}
Background. The blood supply of the stomach is well characterized. Although the posterior gastric artery (PGA) is the second most important artery supplying the upper third of the stomach, the main features and clinical importance of the PGA have not been established. The aim of this study was to use multi-detector row computed tomography (MD-CT) to investigate the features of the PGA with respect to its incidence, location and size, and to correlate the findings with clinical practice.

Methods. In August 2004, 50 preoperative patients (33 men and 17 women) were evaluated prospectively by MD-CT. Informed consent for the present study was accepted at Kochi Medical School. The length of the PGA, from the root of the splenic artery, and the internal diameter of the PGA were examined. Correlations between body mass index (BMI) and the observed features of the PGA were investigated.

Results. The PGA was recognized in all patients. In $49(98 \%)$ patients, the PGA branched from the splenic artery. In $1(2 \%)$ patient, the PGA originated from the root of the celiac trunk. The PGA was discernible for a length of $4.2-14.3 \mathrm{~cm}$ (mean, $9.1 \mathrm{~cm})$ from the root of the splenic artery, and the internal diameter of the PGA was $0.5-2.1 \mathrm{~mm}$ (mean, $1.0 \mathrm{~mm}$ ). BMI did not correlate with PGA length or internal diameter.

Conclusion. Our current study suggested that the anatomical and clinical features of the PGA can be shown by clinical methods, and that these features are useful in planning surgical treatment.
\end{abstract}

Key words Posterior gastric artery (PGA) - Multi-detector row computed tomography (MD-CT) - Gastric carcinoma * Lymph node metastasis

Offprint requests to: $\mathrm{M}$. Kobayashi

Received: December 20, 2004 / Accepted: April 28, 2005

\section{Introduction}

The blood supply of the stomach is well characterized [1-3]. The upper third of the stomach is vascularized by four well-anastomosed main arteries, the left gastric artery, which is the main blood supply of the upper stomach; the posterior gastric artery (PGA); which branches from the splenic artery; the short gastric artery; and the gastroepiploic artery. Although the PGA is the second most important artery supplying the upper third of the stomach, the main features and clinical importance of the PGA are not well established [1,3-9].

The incidence of carcinoma of the gastric cardia is increasing in Japan and in the West [10]. To understand the mechanisms determining the prognosis of gastric carcinoma of the upper third of the stomach, it is important to establish the features and clinical importance of the PGA, as lymphatic drainage vessels connect to the left gastric artery and branches of the splenic artery [11]. The reported incidence of the PGA ranges from $36 \%$ to $84 \%$ [1,3-9]. Contrary to these reports, our previous study, using digital subtraction angiography (DSA), indicated that almost all men had a PGA [12].

The purpose of the present study was to clarify the features of the PGA, including its incidence, location, and size, using multi-detector row computed tomography (MD-CT), and to correlate the findings with clinical practice [13-19].

\section{Patients, materials, and methods}

In August 2004, 50 preoperative patients at our department (33 men and 17 women) were evaluated prospectively by MD-CT. Patients selected for this study had not undergone previous surgical procedures and had provided informed consent to Kochi Medical School. Of these 50 patients, 18 had primary liver carcinoma, 16 had gastric carcinoma, 5 had carcinoma of the biliary 
tract, 4 had pancreatic carcinoma, 4 had colorectal carcinoma, 2 had renal cell carcinoma, and 1 had hepatolithiasis. In the 18 patients with liver carcinoma, the incidence of viral liver cirrhosis was $83.3 \%$ (14 patients had serum hepatitis $\mathrm{C}$ antibody and 1 had serum hepatitis B surface antigen).

Imaging analyses were performed using MD-CT technology, as it has superior diagnostic capability compared with earlier angiography systems. Threedimensional reconstructions of MD-CT images were made and used to prospectively search for features of the PGA. A radiologist and surgeons provided confirmation of the PGA. The length of the PGA, from the root of the splenic artery, and the internal diameter of the PGA were examined. The body mass index (BMI) was calculated by dividing the weight in kilograms by the square of the height in meters. Correlations between BMI and the observed features of the PGA were investigated.

The findings were compared by the $\chi^{2}$ test. A level of $P<0.05$ was considered significant. Correlations between the BMI and the length or internal diameter of the PGA were calculated using the Pearson product moment.

\section{Results}

Of the 50 patients evaluated in this study, 33 were men and 17 were women, ranging in age from 29 to 90 years (mean, 68.8 years). The PGA was recognized in all patients. In 49 (98\%) patients, the PGA branched from the splenic artery (Fig. 1). In 1 (2\%) patient, the PGA originated from the root of the celiac trunk (Fig. 2).

The features of the PGA branching from the splenic artery are shown in Table 1 . The PGA was discernible for a length of $4.2-14.3 \mathrm{~cm}$ (mean, $9.1 \mathrm{~cm}$ ) from the root of the splenic artery, and the internal diameter of the PGA was $0.5-2.1 \mathrm{~mm}$ (mean, $1.0 \mathrm{~mm}$ ). The length of the PGA from the root of splenic artery in males and females was $4.2-14.3 \mathrm{~cm}$ (mean, $9.0 \mathrm{~cm}$ ) and $6.1-13.8 \mathrm{~cm}$ (mean, $9.2 \mathrm{~cm}$ ), respectively. The internal diameter of the PGA in males and females was $0.5-2.1 \mathrm{~mm}$ (mean, $1.0 \mathrm{~mm}$ ) and $0.5-2.1 \mathrm{~mm}$ (mean, $0.9 \mathrm{~mm}$ ), respectively. There was no significant difference in either the length or the internal diameter of the PGA with respect to sex or age.

Consistent with our previous report [12], BMI did not correlate with the PGA length $(r=0.092)$ or internal diameter $(r=0.018)$.

\section{Discussion}

Blood supply to the stomach is well characterized [1-3]. The key nutritional blood vessel of the upper third of

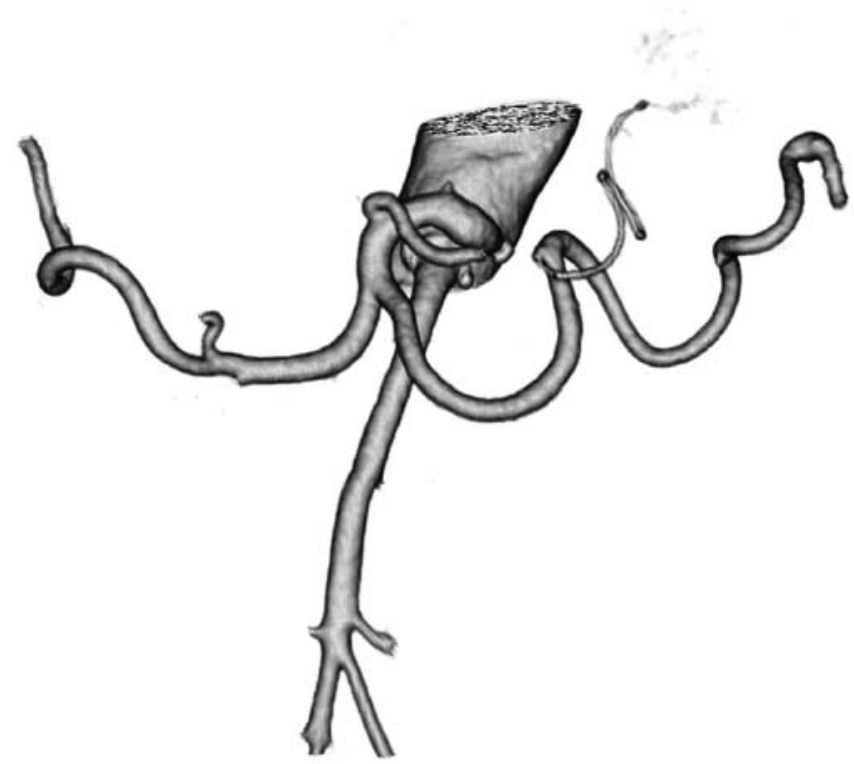

Fig. 1. Posterior gastric artery has branched from the splenic artery

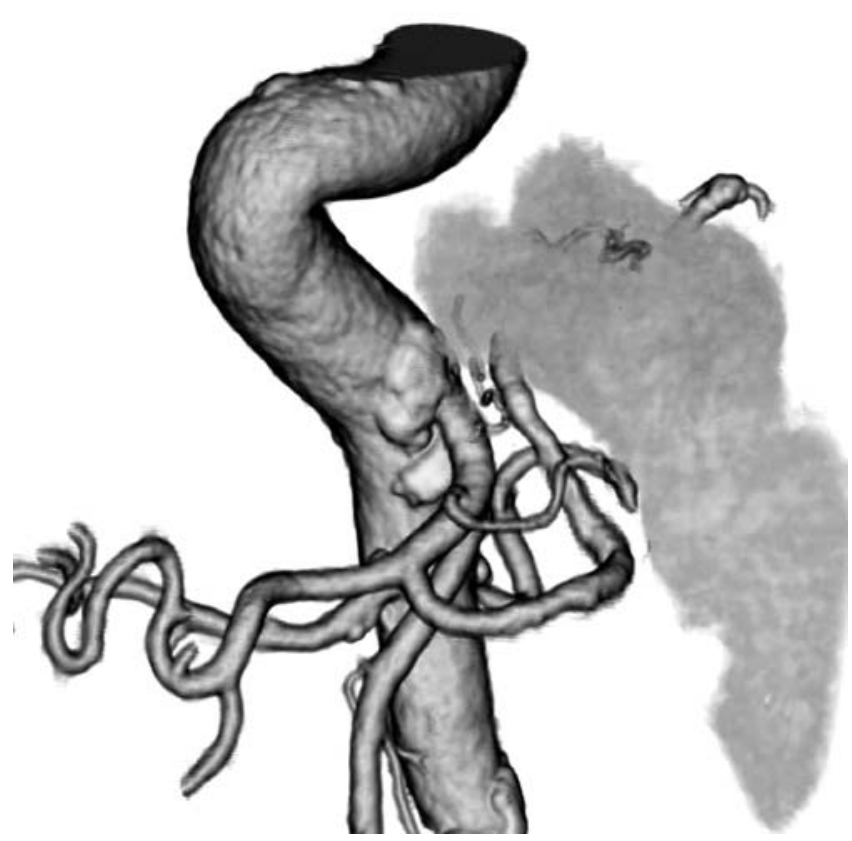

Fig. 2. Posterior gastric artery originated from the root of the celiac trunk

the stomach is the left gastric artery, followed by the PGA, the short gastric artery, and the left gastroepiploic artery. Although the PGA is the second most important artery supplying the upper third of the stomach, the main features and clinical importance of the PGA are not well established, and reports on the incidence of PGA are limited and inconsistent, ranging from $36 \%$ to 
Table 1. Features of PGA, using MD-CT

\begin{tabular}{lcccc}
\hline Characteristics & $\begin{array}{c}\text { No. of } \\
\text { patients }\end{array}$ & $\begin{array}{c}\text { Mean distance from } \\
\text { root of SA }(\mathrm{cm})\end{array}$ & $\begin{array}{c}\text { Mean internal diameter } \\
\text { of PGA }(\mathrm{mm})\end{array}$ & $P$ value \\
\hline $\begin{array}{l}\text { Overall } \\
\text { Sex }\end{array}$ & 49 & $9.1(4.2-14.3)$ & $1.0(0.5-2.1)$ & \\
$\quad \begin{array}{l}\text { Male } \\
\text { Female }\end{array}$ & 33 & $9.0(4.2-14.3)^{1)}$ & $1.0(0.5-2.1)^{3)}$ & 1)-2) 0.4154 \\
$\begin{array}{l}\text { Age (years) } \\
\leq 70\end{array}$ & 16 & $9.2(6.1-13.8)^{2)}$ & $0.9(0.5-2.1)^{4)}$ & 3)-4) 0.2373 \\
$\quad 370$ & 30 & $9.3(4.2-14.0)^{5)}$ & $1.0(0.5-2.0)^{7)}$ & 5)-6) 0.5137 \\
& 19 & $8.7(4.8-14.3)^{6)}$ & $1.0(0.5-2.1)^{8)}$ & 7)-8) 0.8507 \\
\hline
\end{tabular}

Figures in parentheses are ranges

SA, splenic artery; PGA, posterior gastric artery

84\% [1,3-9]. Historically inaccurate detection of the PGA may account for these findings. In the present study, the PGA was detected using MD-CT imaging analysis technology, due to its superior diagnostic capability compared with earlier angiography systems.

Furthermore, the present study employed a strategy in which abdominal surgeons and a radiologist cooperated in the interpretation of results [13-19].

Our previous study, using DSA, indicated that almost all men had a PGA [12]. These findings are inconsistent with other previous reports on the incidence of the PGA [1,3-9]. In the present study, the average length of the PGA was found to be $9.1 \mathrm{~cm}$, which is significantly longer than our previous finding of $5.4 \mathrm{~cm}$, using DSA [12]. Because DSA measures the length of the PGA according to the direction of a tangent, the results obtained with this method are not considered to truly reflect the in vivo situation. The present study supported our previous findings that the PGA usually (in $98 \%$ of patients) branches from the splenic artery. However, according to previous researchers, several patterns of the PGA have been reported, showing that the PGA branched not only from the splenic artery but also from the celiac trunk or the superior polar artery $[4,8]$. These results are important, as an increase in the understanding of the features of PGA increases the success of operations involving the PGA. The length from the root of the splenic artery and the internal diameter of the PGA were not significantly different between males and females, and these measurements showed no correlations with height, weight, or BMI.

Of note, the flow of lymph is the route for lymph node metastasis in gastric cancer. Most major lymphatic vessels in the upper third of the stomach are found along the left gastric artery and then proceed along the PGA and short gastric artery [11]. One of the important issues about the PGA is the number of lymph nodes along the PGA, and metastasis along the PGA. Previous authors have reported that the incidence of lymph node metastasis along the splenic artery ranged from $19.1 \%$ to $31.3 \%$ [20,21]. At our institute, from 1981 to the end of
Table 2. Incidence (\%) of lymph node metastases of gastric carcinoma

\begin{tabular}{lcrrrr}
\hline & $\mathrm{n} 0$ & $\mathrm{n} 1$ & $\mathrm{n} 2$ & $\mathrm{n} 3$ & Overall \\
\hline $\mathrm{t} 1$ & 91.5 & 7.2 & 0.9 & 0.4 & 446 \\
$\mathrm{t} 2$ & 49.3 & 30.3 & 12.7 & 7.7 & 221 \\
$\mathrm{t} 3$ & 15.3 & 31.5 & 32.3 & 20.9 & 124 \\
$\mathrm{t} 4$ & 20.7 & 27.6 & 31.0 & 20.7 & 29 \\
Overall & 542 & 146 & 81 & 51 & 820
\end{tabular}

$\mathrm{n} 0, \mathrm{n} 1, \mathrm{n} 2$, and $\mathrm{n} 3$ were defined according to the Japanese classification of gastric carcinoma by the Japanese Gastric Cancer Association (13th edition) [22]

$\mathrm{t} 1$, tumor is confined to the mucosa and/or submucosa; $\mathrm{t} 2$, tumor invades muscularis propria or subserosa; $\mathrm{t} 3$, tumor invades and penetrates serosa without invasion of adjacent structures; $\mathrm{t} 4$, tumor invades adjacent structures

2003, 820 patients with gastric carcinoma underwent gastrectomy with D2 or D3 lymph node dissection for curative resection. The incidence of lymph node metastasis in these patients is summarized in Table 2. The incidence of lymph node metastasis along the splenic artery (no. 11) in the current study was $17.9 \%$. The lymph nodes of the domain located along the proximal splenic artery are classified as $\mathrm{n} 2$ according to the Japanese classification of gastric carcinoma [22] or TNM.

Interestingly, the PGA of only one of our patients $(2 \%)$ originated directly from the root of the celiac trunk, and this can be considered an anatomical variation (Fig. 2). Of the patients with confirmed lymph node metastases, five had lymph node metastases at the $\mathrm{n} 2$ lymph node station, and not at the $\mathrm{n} 1$ lymph node station, according to the Japanese classification of gastric carcinoma [22]. Lymph node metastases were observed along the proximal splenic artery (no. 11) in two patients, along the left gastric artery (no. 7) in two patients, and along the common hepatic artery (no. 8) in one patient. Lymph node metastases located at the $\mathrm{n} 2$ lymph node station and not at the $\mathrm{n} 1$ station may involve anatomical variation. The incidence of lymph node metastases in patients with an advanced stage of 
gastric carcinoma ( $\mathrm{t} 2, \mathrm{t} 3$, or $\mathrm{t} 4$ tumor) was $64.2 \%$. As lymph node metastasis is one of the main factors determining the prognosis of patients with gastric carcinoma, it is considered important that standard gastrectomy with D2 lymph node dissection be performed for patients with gastric carcinoma where the sentinel lymph node cannot be identified, and for those with advancedstage gastric carcinoma [23-29].

The capacity for early detection of gastric carcinoma has increased gradually according to progress in diagnostic techniques and equipment. Early gastric carcinoma accounts for $4 \%-16 \%$ of all gastric carcinoma cases in the West, and 30\%-50\% in Japan [30-32]. The findings from the present study are important, as less invasive and more successful surgery for early gastric carcinoma is possible with both an accurate knowledge of sentinel lymph node location in gastric carcinoma and an understanding of anatomical variation. Findings from this study also highlight the importance of sophisticated technology, such as MD-CT, to allow the identification of sentinel lymph node location [33-35].

\section{References}

1. Vandamme JP, Bonte J. The blood supply of the stomach. Acta Anat (Basel) 1988;131:89-96.

2. Vandamme JP, Bonte J. Systematisation of the arteries in the splenic hilus. Acta Anat (Basel) 1986;125:217-24.

3. DiDio LJ, Christoforidis AJ, Chandnani PC. Posterior gastric artery and its significance as seen in angiograms. Am J Surg 1980;139:333-7.

4. Pitynski K, Skawina A, Lipczynski W, Polakiewicz J, Walocha J. The posterior gastric and superior polar arteries in human fetuses. Folia Morphol (Warsz) 1996;55:43-9.

5. Trubel W, Turkof E, Rokitansky A, Firbas W. Incidence, anatomy and territories supplied by the posterior gastric artery. Acta Anat (Basel) 1985;124:26-30.

6. Berens AS, Aluisio FV, Colborn GL, Grey SW, Skandalakis JE. The incidence and significance of the posterior gastric artery in human anatomy. J Med Assoc Ga 1991;80:425-8.

7. Yu W, Whang I. Surgical implication of the posterior gastric artery. Am J Surg 1990;159:420-2.

8. Trubel W, Rokitansky A, Turkof E, Firbas W. Correlations between posterior gastric artery and superior polar artery in human anatomy. Anat Anz 1988;167:219-23.

9. Suzuki K, Prates JC, DiDio LJ. Incidence and surgical importance of the posterior gastric artery. Ann Surg 1978;187:134-6.

10. Okabayashi T, Gotoda T, Kondo H, Inui T, Ono H, Saito D, et al. Early carcinoma of the gastric cardia in Japan: is it different from that in West? Cancer 2000;89:2555-9.

11. Nakagawa N. Rationale for dissection of lymph node associated with gastric carcinoma located at the greater curvature of the stomach - the correlation between the pattern of lymph node metastasis and the distribution of blackened lymph node by vital staining using activated carbon particles ( $\mathrm{CH} \mathrm{40)} \mathrm{(in} \mathrm{Japanese)}$ Jpn J Gastroenterol Surg 1992;25:2460-9.

12. Okabayashi T, Kobayashi M, Sugimoto T, Ohara S, Okamoto K, Matsuura K, et al. Posterior gastric artery in angiograms and its surgical importance. Hepatogastroenterology 2005;52:298-301.

13. Stemmler BJ, Paulson EK, Thornton FJ, Winters SR, Nelson RC, Clary BM. Dual-Phase 3D MDCT angiography for evaluation of the liver before hepatic resection. AJR Am J Roentgenol 2004; 183:1551-7.

14. Duddalwar VA. Multislice CT angiography: a practical guide to $\mathrm{CT}$ angiography in vascular imaging and intervention. Br J Radiol 2004;77(Suppl 1):S27-38.

15. Guven K, Acunas B. Multidetector computed tomography angiography of the abdomen. Eur J Radiol 2004;52:44-55.

16. Napoli A, Fleischmann D, Chan FP, Catalano C, Hellinger JC, Passariello R, et al. Computed tomography angiography: state-ofthe-art imaging using multidetector-row technology. J Comput Assist Tomogr 2004;28(Suppl 1):S32-45.

17. Guan YS, Zheng XH, Zhou XP, Huang J, Sun L, Chen X, et al. Multidetector CT in evaluating blood supply of hepatocellular carcinoma after transcatheter arterial chemoembolization. World J Gastroenterol 2004;10:2127-9.

18. Matsuki M, Kani H, Tatsugami F, Yoshikawa S, Narabayashi I, Lee SW, et al. Preoperative assessment of vascular anatomy around the stomach by 3D imaging using MDCT before laparoscopy-assisted gastrectomy. AJR Am J Roentgenol 2004; 183:145-51.

19. Foley WD, Kerimoglu U. Abdominal MDCT: liver, pancreas, and biliary tract. Semin Ultrasound CT MR 2004;25:122-44.

20. Kato M. Study on feeding arteries and lymphatic drainage of remnant stomach cancer using angiography and fine activated carbon particles (in Japanese with English abstract). Nippon Geka Gakkai Zasshi (J Jpn Surg Soc) 1995;96:80-7.

21. Katai H, Maruyama K, Sasako M, Sano T. Incidence of nodal metastasis around the superior border of the pancreas based on number of metastatic perigastric nodes. Gastric Cancer 1998;1: $115-7$.

22. Japanese Gastric Cancer Association; Japanese classification of gastric carcinoma 13th ed. Tokyo, Kanehara; 1999.

23. Arai K, Iwasaki Y, Takahashi T. Clinicopathological analysis of early gastric cancer with solitary lymph node metastasis. Br J Surg 2002;89:1435-7.

24. Gotoda T, Yanagisawa A, Sasako M, Ono H, Nakanishi Y, Shimoda T, et al. Incidence of lymph node metastasis from gastric cancer: estimation with a large number of cases at two large centers. Gastric Cancer 2000;3:219-25.

25. Choi HJ, Kim YH, Kim SS, Hong SH. Occurrence and prognostic implications of micrometastases in lymph nodes from patients with submucosal gastric carcinoma. Ann Surg Oncol 2002;9:139.

26. Shimada S, Yagi Y, Honmyo U, Shiomori K, Yoshida N, Ogawa M. Involvement of three or more lymph nodes predicts poor prognosis in submucosal gastric carcinoma. Gastric Cancer 2001; 4:54-9.

27. Seto Y, Shimoyama S, Kitayama J, Mafune K, Kaminishi M, Aikou T, et al. Lymph node metastasis and preoperative diagnosis of depth of invasion in early gastric cancer. Gastric Cancer 2001;4:34-8.

28. Sano T, Sasako M, Yamamoto S, Nashimoto A, Kurita A, Hiratsuka M, et al. Gastric cancer surgery: morbidity and mortality results from a prospective randomized controlled trial comparing D2 and extended para-aortic lymphadenectomy - Japan Clinical Oncology Group study 9501. J Clin Oncol 2004;22:276773.

29. Yamaguchi T, Sano T, Katai H, Sasako M, Maruyama K. Nodepositive mucosal gastric cancer: a follow-up study. Jpn J Clin Oncol 2001;31:153-6.

30. Popiela T, Kulig J, Kolodziejczyk P, Sierzega M. Long-term results of surgery for early gastric cancer. Br J Surg 2002;89:103542.

31. Borie F, Millat B, Fingerhut A, Hay JM, Fagniez PL, Sazce BD, et al. Lymphatic involvement in early gastric cancer. Arch Surg 2000;135:1218-23.

32. Folli S, Margagni P, Roviello F, De Manzoni G, Marrelli D, Saragoni L, et al. for the Italian Research Group for Gastric Cancer (IRGGC). Risk factors for lymph node metastases and 
their prognostic significance in early gastric cancer (EGC). Jpn J Clin Oncol 2001;31:495-9.

33. Osaka H, Yashiro M, Sawada T, Katsuragi K, Hirakawa K. Is a lymph node detected by the dye-guided method a true sentinel node in gastric cancer? Clin Cancer Res 2004;10:6912-18.

34. Isozaki H, Kimura $\mathrm{T}$, Tanaka $\mathrm{N}$, Satoh $\mathrm{K}$, Matsumoto $\mathrm{S}$, Ninomiya M, et al. An assessment of the feasibility of sentinel lymph node-guided surgery for gastric cancer. Gastric Cancer 2004;7:149-53.

35. Kim MC, Kim HH, Jung GJ, Lee JH, Choi SR, Kang DY, et al. Lymphatic mapping and sentinel node biopsy using $99 \mathrm{mTc}$ tin colloid in gastric cancer. Ann Surg 2004;239:383-7. 